\title{
Medicina del Deporte
}

\author{
Sports Medicine
}

\section{MD-1}

\section{CARACTERISTICAS CINEANTROPOMÉTRICAS Y CARDIOVASCULARES EN TRIATLETAS DE MEDELLIN}

\author{
POLANCO JUAN PABLO, ROSERO RICARDO, CORTÉS DAVID , \\ POLANCO JUAN PABLO, JARAMILLO ADRIANA, COSSIO ISABEL, \\ PALACIO JORGE.
}

Clínica de Obesidad, Dismetabolismo y Deporte - COD², Clínica Las Américas, Medellín, Colombia.

Introducción. El triatlón es un deporte formado por 3 disciplinas que son natación, ciclismo y trote, gracias a estas combinaciones las características físicas y fisiológicas de los deportistas son muy variadas. Generalmente tienen bajo porcentaje de grasa corporal pareciéndose mucho a la genética de los ciclistas; Pueden llegar a tener consumos máximos de oxígeno que oscilan entre 65-75 mililitros/kilogramo de peso/minuto, aunque en los principiantes pueden ser menores. Algunos inclusive pueden llegar a tasas tan elevados de $80-85 \mathrm{ml} / \mathrm{kg} / \mathrm{min}$ y en los tres segmentos de la prueba son capaces de rendir a niveles próximos a su umbral anaeróbico, e incluso en ocasiones, por encima.

Diseño. Estudio observacional descriptivo de serie de casos.

Métodos. Se realizó muestreo por conveniencia, incluyendo 15 triatletas procedentes de la ciudad de Medellín (Antioquia), Colombia, durante el año 2018, que consultaron Clínica de Obesidad, Dismetabolismo y Deporte. Para el análisis estadístico se utilizó MicrosoftÒ Excel para Mac Versión 16.13, y R (The R Project for Statistical Computing) versión 3.5.0.

Resultados. La edad media de los participantes fue 32,2 años, mediana de 31 años, moda de 26 años y desviación estándar 6,76 años. El IMC promedio fue de 24,52 $\mathrm{kg} / \mathrm{m}^{2}$, mediana de $24,34 \mathrm{~kg} / \mathrm{m}^{2}$, desviación estándar de $3,21 \mathrm{~kg} / \mathrm{m}^{2}$. El $33.3 \%$ de los participantes en el estudio tienen $\mathrm{IMC}^{3} 25 \mathrm{~kg} / \mathrm{m}^{2}$. El consumo promedio de $\mathrm{VO} 2$ promedio $64,83 \mathrm{ml} / \mathrm{kg} / \mathrm{min}$., mediana $83,3 \mathrm{ml} / \mathrm{kg} / \mathrm{min}$., moda $83,3 \mathrm{ml} / \mathrm{kg} / \mathrm{min}$., desviación estándar $28,59 \mathrm{ml} / \mathrm{kg} / \mathrm{min}$.

Conclusiones. Se evidenció que los triatletas estudiados en la ciudad de Medellín tienen consumos de VO2 similares a de los sujetos reportados en diferentes series de casos y que pese a que en algunos atletas la composición física y corporal no reflejaría un buen rendimiento los consumos de oxígenos no se relacionan. 